International Journal of Cancer Studies \& Research (IJCR)

ISSN: $2167-9118$

\title{
Apoptotic Cell Clearance: An Orchestra With Still Too Many Unknown Players
}

Editorial

Preta $G^{*}$

Institute of Life Science, School of Medicine, Swansea University, Swansea, United Kingdom.

\section{*Corresponding Author:}

\section{Giulio Preta}

Institute of Life Science, School of Medicine, Swansea University, Swansea, United Kingdom.

E-mail: g.preta@swansea.ac.uk

Received: June 04, 2014

Published: June 26, 2014

Citation: Preta G (2014) Apoptotic Cell Clearance: An Orchestra With Still Too Many Unknown Players. Int J Cancer Stud Res. 3(1e), 1-2. doi: http://dx.doi.org/10.19070/2167-9118-140005e

Copyright: Preta $\mathbf{G}^{\circ}$ 2014. This is an open-access article distributed under the terms of the Creative Commons Attribution License, which permits unrestricted use, distribution and reproduction in any medium, provided the original author and source are credited.

Apoptotic cells are removed by a process involving recognition and phagocytosis by professional phagocytes or neighbouring cells, followed by the induction of an active anti-inflammatory response. These events are critical for efficient corpse elimination and to prevent the release of potentially cytotoxic cellular contents that could elicit an autoimmune response: defects in apoptotic cell clearance are often associated with autoimmune or chronic inflammatory diseases [1]. Moreover, high levels of cell death occur within a tumour environment and the mechanisms through which dying tumour cells are removed can considerably influence tumour-specific immunity [2].

It is indisputable that several new studies had shed new light in the molecular mechanisms leading to phosphatidylserine (PtdSer) exposure and recognition. For example, different PtdSer receptors on macrophage are continuously being identified, in addition to the original PtdSer receptor cloned by Fadok and colleagues [3]: TIM-1 and TIM-4 [4], stabilin-2 [5] and bridging molecules like MFG-E8 in mammalian cells [6] or TTR-52 in Caenorbabditis Elegans [7] are shown to be able to interact with PtdSer and influence the removal of the cell corpse.

Different lipid transporter activities have been implicated in the generation, maintenance and alteration of phospholipid asymmetry in the plasma membrane which are essential for regulating a plethora of cellular events [8]. However, the challenge for scientists remains to assign these activities to specific molecular entities, since often discrepancies are found. According to one study [9] the transmembrane protein 16F (TMEM16F) has the calcium dependent phospholipid scramblase activity and when lymphoma cells were transformed with a constitutively active form of TMEM16F, they expose levels of PtdSer comparable to that observed in apoptotic cells. More recently it was demonstrated that TMEM16F forms a $\mathrm{Ca}(2+)$ activated cation chan- nel required for lipid scrambling since TMEM16F KO mice are defective in PtdSer exposure, hemostasis and thrombosis [10]. Another controversy is on the role of apoptotic blebbing in promoting cell clearance: in vitro studies reported that inhibition of apoptotic blebbing compromised clearance by macrophages [11]. However, impaired corpse clearance following defective blebbing could be easily rescued by the PtdSer-bridging protein MFG-E8 suggesting the presence of redundancy in clearing mechanisms [12]. It should be underlined the similarity between the worm $C$ Elegans and humans since the human blebs, which focalize factors that promote clearance, resemble the extracellular PtdSer vesicles, which lead to the exoplasmic leaflet expression on phagocytes via TTR-52 and CED-1 [7]. Therefore it seems that a better understanding of cell clearance could be derived from further studies in $C$ Elegans, in addition to our actual knowledge on the apoptotic process, based on pioneering studies performed by Horvitz and colleagues [13]. But which points need to be addressed primarily? As well as an orchestra, programmed cell clearance is composed of several players acting synergistically under the supervision of a director. Despite the director in apoptotic cell clearance has been identified as PtdSer exposure, the key signal promoting this process, rising evidences suggest that other players are essential "to play". Identification of these players is the basis for therapeutic intervention by a selective targeting which must always take into consideration the specific pathology, since, under the current state of knowledge, there is no drug that modulates programmed cell death, effective for different diseases. Furthermore, attention should be focused also on the phagocytes factors that may influence continued clearance: recently it was shown that the mitochondrial membrane potential of the phagocyte critically controls engulfment capacity, with lower potential enhancing engulfment and vice versa [14]. This finding has a remarkable importance since suggests that mitochondria are crucial organelles in the programmed cell clearance [15] acting at both sides of the 'phagocytic synapse'.

\section{References}

[1]. Elliott MR, Ravichandran KS. (2010) Clearance of apoptotic cells: implications in health and disease. J Cell Biol 189:1059-1070.

[2]. Poon IK, Lucas CD, Rossi AG, Ravichandran KS. (2014) Apoptotic cell clearance: basic biology and therapeutic potential. Nat Rev Immunol 14:166-180.

[3]. Fadok VA, Bratton DL, Rose DM, Pearson A, Ezekewitz RA, et al. (2000) A receptor for phosphatidylserine-specific clearance of apoptotic cells. Nature 405:85-90.

[4]. Kobayashi N, Karisola P, Pena-Cruz V, Dorfman DM, Jinushi M, et al. (2007) TIM-1 and TIM-4 glycoproteins bind phosphatidylserine and mediate uptake of apoptotic cells. Immunity 27:927-940.

[5]. Park SY, Jung MY, Kim HJ, Lee SJ, Kim SY, et al (2008) Rapid cell corpse clearance by stabilin-2, a membrane phosphatidylserine receptor. Cell death and differentiation 15:192-201.

[6]. Borisenko GG, Iverson SL, Ahlberg S, Kagan VE, Fadeel B. (2004) Milk fat globule epidermal growth factor 8 (MFG-E8) binds to oxidized phos- 
phatidylserine: implications for macrophage clearance of apoptotic cells. Cell death and differentiation 11:943-945.

[7]. Mapes J, Chen YZ, Kim A, Mitani S, Kang BH, et al. (2012) CED-1, CED7, and TTR-52 regulate surface phosphatidylserine expression on apoptotic and phagocytic cells. Current biology : CB 22:1267-1275.

[8]. Fadeel B, Xue D. (2009) The ins and outs of phospholipid asymmetry in the plasma membrane: roles in health and disease. Critical reviews in biochemistry and molecular biology 44:264-277.

[9]. Segawa K, Suzuki J, Nagata S. (2011) Constitutive exposure of phosphatidylserine on viable cells. Proceedings of the National Academy of Sciences of the United States of America 108:19246-19251.

[10]. Yang H, Kim A, David T, Palmer D, Jin T, et al. (2012) TMEM16F Forms a $\mathrm{Ca}(2+)$-Activated Cation Channel Required for Lipid Scrambling in Platelets during Blood Coagulation. Cell 151, 111-122.

[11]. Orlando KA, Stone NL, Pittman RN. (2006) Rho kinase regulates fragmentation and phagocytosis of apoptotic cells. Experimental cell research 312:
$5-15$.

[12]. Witasp E, Uthaisang W, Elenstrom-Magnusson C, Hanayama R, Tanaka M, et al. (2007) Bridge over troubled water: milk fat globule epidermal growth factor 8 promotes human monocyte-derived macrophage clearance of nonblebbing phosphatidylserine-positive target cells. Cell death and differentiation 14:1063-1065.

[13]. Metzstein MM, Stanfield GM, Horvitz HR. (1998) Genetics of programmed cell death in $C$ Elegans: past, present and future. Trends in genetics : TIG 14:410-416.

[14]. Park D, Han CZ, Elliott MR, Kinchen JM, Trampont PC, et al. (2011) Continued clearance of apoptotic cells critically depends on the phagocyte Ucp2 protein. Nature 477: 220-224.

[15]. Preta G, Fadeel B. (2012) AIF and Scythe (Bat3) regulate phosphatidylserine exposure and macrophage clearance of cells undergoing Fas (APO-1)-mediated apoptosis. 7(10): e47328. 